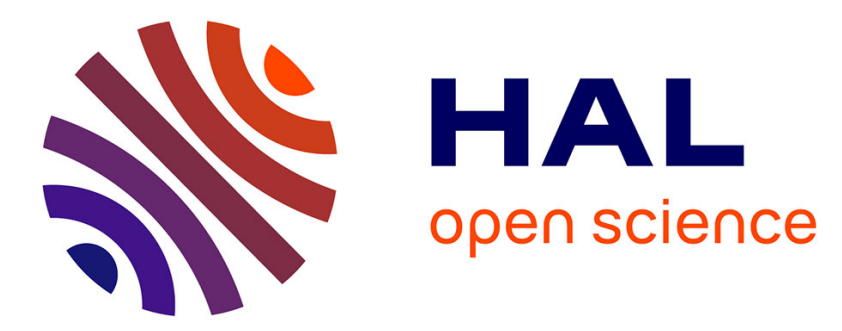

\title{
An insight into the charge carriers transport properties and electric field distribution of $\mathrm{CH} 3 \mathrm{NH} 3 \mathrm{PbBr} 3$ thick single crystals
}

Oriane Baussens, Loli Maturana, Smaïl Amari, Julien Zaccaro, Jean-Marie Verilhac, Lionel Hirsch, Eric Gros-Daillon

\section{To cite this version:}

Oriane Baussens, Loli Maturana, Smaïl Amari, Julien Zaccaro, Jean-Marie Verilhac, et al.. An insight into the charge carriers transport properties and electric field distribution of $\mathrm{CH} 3 \mathrm{NH} 3 \mathrm{PbBr} 3$ thick single crystals. Applied Physics Letters, 2020, 117 (4), pp.041904. 10.1063/5.0011713 . hal-02947932

\section{HAL Id: hal-02947932 \\ https://hal.science/hal-02947932}

Submitted on 30 Sep 2020

HAL is a multi-disciplinary open access archive for the deposit and dissemination of scientific research documents, whether they are published or not. The documents may come from teaching and research institutions in France or abroad, or from public or private research centers.
L'archive ouverte pluridisciplinaire $\mathbf{H A L}$, est destinée au dépôt et à la diffusion de documents scientifiques de niveau recherche, publiés ou non, émanant des établissements d'enseignement et de recherche français ou étrangers, des laboratoires publics ou privés. 


\section{AUTHOR QUERY FORM}

\begin{tabular}{|l|l|l|}
\hline & Journal: Appl. Phys. Lett. & $\begin{array}{c}\text { Please provide your responses and any corrections } \\
\text { by annotating this PDF and uploading it to AIP's } \\
\text { Publishing }\end{array}$ \\
eProof website as detailed in the Welcome email. \\
Article Number: APL20-AR-03618
\end{tabular}

Dear Author,

Below are the queries associated with your article; please answer all of these queries before sending the proof back to AIP.

Article checklist: In order to ensure greater accuracy, please check the following and make all necessary corrections before returning your proof.

1. Is the title of your article accurate and spelled correctly?

2. Please check affiliations including spelling, completeness, and correct linking to authors.

3. Did you remember to include acknowledgment of funding, if required, and is it accurate?

\begin{tabular}{|c|c|}
\hline $\begin{array}{l}\text { Location in } \\
\text { article }\end{array}$ & $\begin{array}{l}\text { Query / Remark: click on the Q link to navigate } \\
\text { to the appropriate spot in the proof. There, insert your comments as a PDF annotation. }\end{array}$ \\
\hline & $\begin{array}{l}\text { Please check that the author names are in the proper order and spelled correctly. Also, please ensure that each } \\
\text { author's given and surnames have been correctly identified (given names are highlighted in red and surnames } \\
\text { appear in blue). } \\
\text { Please check and confirm presentation of affiliation } 3 . \\
\text { Please provide complete details for Ref. } 2 \text {. } \\
\text { Please provide volume and page number for Ref. } 4 . \\
\text { Please provide publisher name for Ref. } 13 \text {. } \\
\text { Please provide book title for Ref. } 14 \text {. } \\
\text { Please confirm ORCIDs are accurate. If you wish to add an ORCID for any author that does not have one, you may do so } \\
\text { now. For more information on ORCID, see https://orcid.org/. } \\
\text { Oriane Baussens - 0000-0003-0042-2855 } \\
\text { Loli Maturana - 0000-0002-4324-123X } \\
\text { Smail Amari - 0000-0002-5565-9481 } \\
\text { Julien Zaccaro- } \\
\text { Jean-Marie Verilhac- } \\
\text { Lionel Hirsch - 0000-0003-2325-5535 } \\
\text { Eric Gros-DAillon - 0000-0002-4196-7854 }\end{array}$ \\
\hline & $\begin{array}{l}\text { Please check and confirm the Funder(s) and Grant Reference Number(s) provided with your submission: } \\
\text { Horizon } 2020 \text { Framework Programme, Award/Contract Number } 777222 \\
\text { Please add any additional funding sources not stated above: }\end{array}$ \\
\hline
\end{tabular}

Thank you for your assistance. 


\title{
An insight into the charge carriers transport properties and electric field distribution of $\mathrm{CH}_{3} \mathrm{NH}_{3} \mathrm{PbBr}_{3}$ thick single crystals $\mathbb{E}$
}

\author{
Cite as: Appl. Phys. Lett. 117, 000000 (2020); doi: 10.1063/5.0011713 \\ Submitted: 30 April 2020 • Accepted: 30 June 2020 . \\ Published Online: 0 Month 0000
}

Oriane Baussensia) and Eric Gros-DAillon, a) (ID

\section{AFFILIATIONS}

'University Grenoble Alpes, CEA, LETI, F38000 Grenoble, France

${ }^{2}$ University Grenoble Alpes, CEA, LITEN, F38000 Grenoble, France

${ }^{3}$ University Grenoble Alpes, CNRS, Grenoble INP, Institut Néel, BP166, 38042 Grenoble, Cedex 09, France

${ }^{4}$ University Bordeaux, IMS-CNRS, UMR 5218, Bordeaux INP, ENSCBP, F33405 Talence, France

a) Authors to whom correspondence should be addressed: oriane.baussens@cea.fr and eric.grosdaillon@cea.fr

\begin{abstract}
Thanks to their unique combination of semiconducting properties and a large cross section for energetic photons, metal halide perovskites could theoretically achieve high $\mathrm{x}$-ray to charge carriers conversion rates, making them materials of high interest for the direct $\mathrm{x}$-ray detection. In this work, we focus on the transport properties of methylammonium lead tribromide $\left(\mathrm{MAPbBr}_{3}\right)$ single crystals. Time of Flight measurements and $\mathrm{x}$-ray focused experiments along the edge of the samples were carried out. We report homogenous holes transit throughout the thickness of the samples as well as poor electrons transit. We also report the continuity of the electric field throughout the thickness of the $\mathrm{MAPbBr}_{3}$ samples, and we present preliminary fitting results to discuss its nature.
\end{abstract}

Published under license by AIP Publishing. https://doi.org/10.1063/5.0011713

Semiconducting metal halide perovskites have gained a lot of interest for solar cells applications. In the last decade, the reported efficiency perovskite based solar cells has increased from $3.81 \%$ to $25.2 \% .{ }^{1,2}$ However, the main concern for such mainstream application, as mentioned by Li et al., is the presence of heavy metals in the ionic crystal. $^{3}$ On the other hand, heavy atoms like lead have large $\mathrm{x}$-rays cross sections. Therefore, heavy metal halide perovskites could be perfectly suited for confined applications such as direct x-ray detectors for medical imaging. In addition to the cross section, efficient $\mathrm{x}$-ray detection also requires good charge carriers' transport properties in order to optimize charge collection and reduce ghosting effect.

In this work, we investigated the photocarriers' transport properties of thick methylammonium lead tribromide $\left(\mathrm{MAPbBr}_{3}\right)$ single crystals. We studied the electron and hole mobilities with laser Time of Flight. The continuity of the electric field throughout the thickness of the samples was then tested by x-ray focused experiments, the first to be reported to our knowledge.

Several $\mathrm{MAPbBr}_{3}$ single crystals of controlled quality were grown individually by a seeded Inverse Temperature Crystallization method. The growth procedure and crystal quality are detailed in a previous publication by Amari et al.. ${ }^{4}$ The obtained single crystals had a typical size of $4 \mathrm{~mm} \times 4 \mathrm{~mm} \times 2 \mathrm{~mm}$. Their top and bottom (100) faces were optically polished (roughness below $30 \mathrm{~nm}$ r.m.s), and chromium electrodes were thermally evaporated on both sides $(100 \mathrm{~nm}$ on one side, $30 \mathrm{~nm}$ on the other to ensure semi-transparency). Six samples were prepared in that way, and their individual properties and $\mathrm{I}-\mathrm{V}_{\text {dark }}$ curves can be found in Figs. S1 and S2 of the supplementary material.

Time of Flight (ToF) is widely used to measure the mobility of carriers in semiconductors. Published ToF mobility values of $\mathrm{MAPbBr}_{3}$ single crystals range from 14 to $217 \mathrm{~cm}^{2} \mathrm{~V} \mathrm{~s}^{-1}$ for holes and $25-190 \mathrm{~cm}^{2} \mathrm{~V}^{-1} \mathrm{~s}^{-1}$ for electrons. ${ }^{5-12}$ When conducting ToF experiments (Fig. 1), the mobility is deduced from the transit time $\left(t_{t}\right)$ of the charge carriers. In laser ToF, the carriers are photogenerated by a laser pulse in the immediate vicinity of a semi-transparent electrode: the incident wavelength is selected so as to be absorbed at depths negligible when compared to the thickness of the sample. That way, only one type of charge carriers contributes to the photocurrent by transiting through the thickness $(L)$ of the sample to reach the opposite electrode. For a sample biased at voltage $V$ with no trapping mechanism and a homogenous electric field, the drift mobility $\mu$ is defined as 


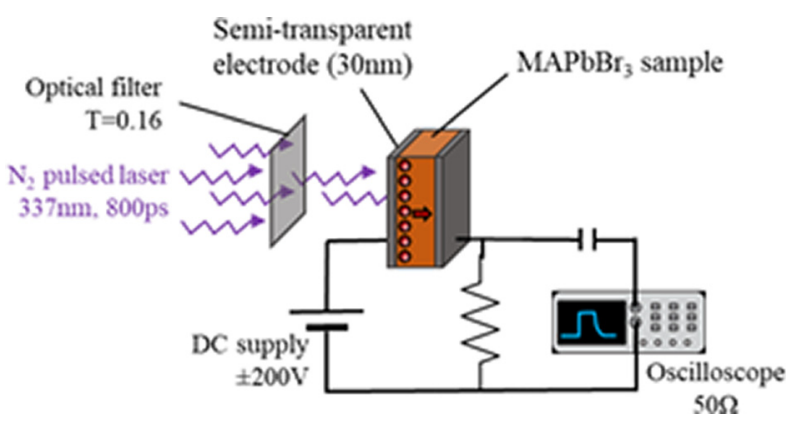

FIG. 1. Laser ToF experiment in a hole measurement configuration.

$$
\mu=L^{2} /\left(V \times t_{t}\right)\left(\mathrm{cm}^{2} \cdot \mathrm{V}^{-1} \cdot \mathrm{s}^{-1}\right) .
$$

In ToF experiments, because a large number of charge carriers are created in a narrow volume $\left(\approx 10^{-2} \mathrm{~cm}^{3}\right)$ near the irradiated electrode, the concentration of charges can lead to a drastic drop of the internal electric field that would reduce the transit time measured. To probe this point, the ToF photocurrent for holes for different amounts of photocarriers generated (estimation of which can be found in page 2 of the supplementary material) was measured. To that end, the incident laser intensity was varied using optical filters with transmittance $(T)$ between 0.1 and 0.5 . From the resulting photocurrent transit curves presented in Fig. 2, three observations can be made. First, the transit time of holes in sample $1\left(\mathrm{t}_{\mathrm{t}-\mathrm{h}+} \sim 7.5 \mu \mathrm{s}\right)$ does not depend on the light intensity for the range of fluxes used. This ensures that under our experimental conditions the photocarriers created by the laser do not perturb the internal electric field. Second, the photocurrent increases from anode to cathode independently of the transmittance (see normalized Fig. S3). Knowing that the instantaneous mobility establishes a link between the photocurrent and the position of the photocarriers at every moment in time, we can attribute the increase in the photocurrent to an increase in the internal electric field from anode to cathode. A more detailed discussion on the nature of the electric field is presented in the $\mathrm{x}$-ray focused experimental section and in the supplementary material. Third, there is a sharp peak at the beginning of the photocurrent. It was attributed it to fast trapping mechanisms in a previous publication. ${ }^{13}$

So, in agreement with these first observations, to characterize the charge carriers mobility, we illuminated our samples with 800 ps

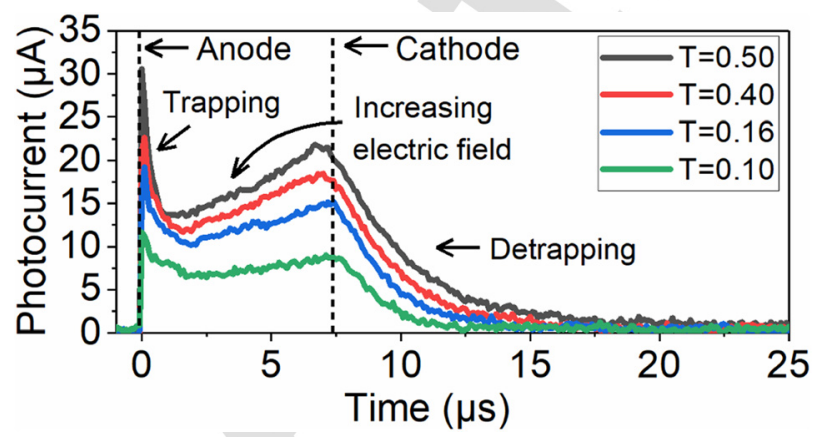

FIG. 2. Hole transit photocurrent of sample 1 biased at $-100 \mathrm{~V}$ as a function of the transmittance of the optical filter. pulses from a nitrogen laser $(337 \mathrm{~nm})$, using the optical filter with a transmittance of 0.16 . Results for our six samples are detailed in the supplementary material (Fig. S4 for holes and Fig. S5 for electrons). Figure 3(a) shows the hole transit photocurrent of sample 1 polarized between $-60 \mathrm{~V}$ and $-140 \mathrm{~V}$. The inflection indicating hole collection at the cathode is clearly visible, and the longest transit time measured is $13 \mu \mathrm{s}$. This value corresponds to a minimum value of the holes' lifetime in our experimental conditions. Holes' mobility measurements were reproducible among our six samples of the same crystal quality with an average of $13 \mathrm{~cm}^{2} \mathrm{~V}^{-1} \mathrm{~s}^{-1} \pm 2 \mathrm{~cm}^{2} \mathrm{~V}^{-1} \mathrm{~s}^{-1}$. Figure $3(\mathrm{~b})$ shows the electron transit photocurrent of sample 1 for bias voltages between $+100 \mathrm{~V}$ and $+140 \mathrm{~V}$. Electrons' mobility could not be measured satisfactorily, because the inflection of the transit photocurrent was not visible even in a log $-\log$ representation (Fig. S6). This indicates that the mobility lifetime product of electrons $\left(\mu_{\mathrm{e}}-\tau_{\mathrm{e}}\right)$ is not large enough to 103 allow all the electrons to fully transit even at polarization fields as high as $1500 \mathrm{~V} \mathrm{~cm}^{-1}$. To estimate a maximal value for the electrons' lifetime, a Ramo's model was used [Eq. (2)]:

$$
i(t)=n e \mu V \times \exp \left(-\frac{t}{\tau}\right) / L^{2} .
$$

In this equation, $n$ is the number of photocarriers created, $e$ is the ele- 107 mentary charge, $\mu$ is the charge carrier mobility, $V$ is the bias voltage, 108 $L$ is the thickness of the sample, and $\tau$ is the charge carrier lifetime. 109 Using Eq. (2) and our experimental conditions, we tried to fit the mea- 110 sured photocurrent for different electron lifetimes. For lifetimes above 111 $1.25 \mu \mathrm{s}$, it was impossible to model the experimental data regardless of 112 the mobility and the bias voltage used. Therefore, we hypothesize that 113 in our experimental conditions the electron lifetime is smaller than 114 $1.25 \mu \mathrm{s}$. The inset of Fig. 3(b) displays the electron photocurrent at 115 $+140 \mathrm{~V}$ and the corresponding Ramo model for a lifetime of $1.25 \mu \mathrm{s}$. 116

For the case at hand, we conclude that $\mu_{\mathrm{e}-} \tau_{\mathrm{e}-} \ll \mu_{\mathrm{h}+} \tau_{\mathrm{h}+}$. This 117 conclusion as implications on the commonly used Hecht fittings, 118 $\begin{array}{ll}\text { which we discuss in the supplementary material (Fig. S7). } & 119\end{array}$

Using ToF experiments, a non-homogenous, anode to cathode 120 increasing electric field was hypothesized. However, because ToF mea- 121 surements are not spatially resolved, the continuity of the electric 122 field in the volume and the position of the cathode are not 123 assured. Therefore, additional X-ray focused experiments were con- 124 ducted (Fig. 4) to verify the continuity and homogeneity of the electric 125 field. They consist in scanning the thickness of a sample with an X-ray 126 beam limited by $100 \mu \mathrm{m}$ slit. The irradiation starts at one edge of the 127
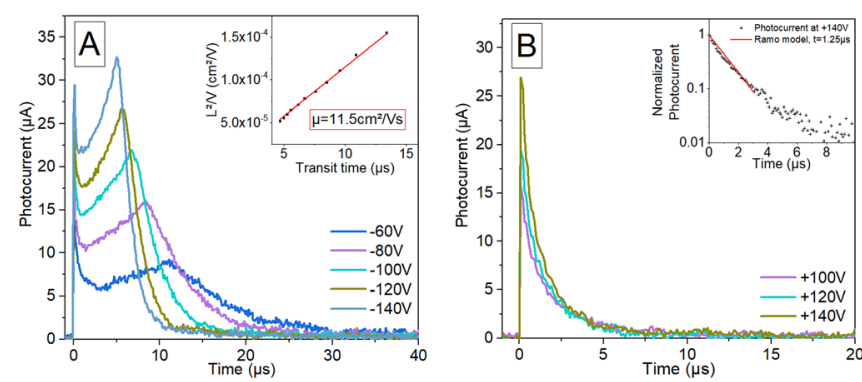

FIG. 3. (a) ToF hole photocurrent of a MAPbBr3 sample (inset: mobility calculation). (b) ToF electron photocurrent of a MAPbBr3 sample (inset: photocurrent at $+140 \mathrm{~V}$ and Ramo model for $\tau_{\mathrm{e}-}=1.25 \mu \mathrm{s}$ ). 


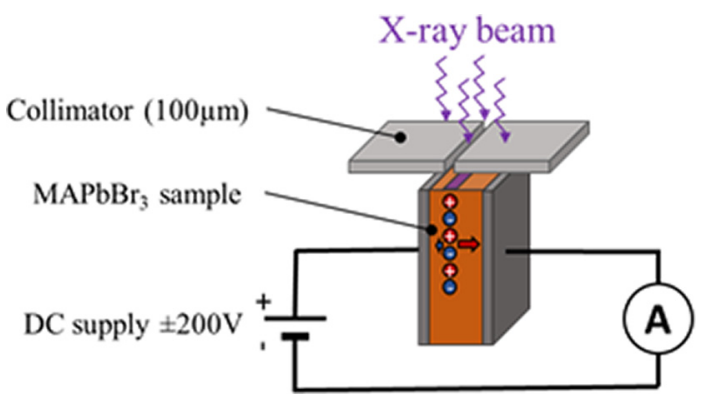

FIG. 4. X-ray focused experiment setup.

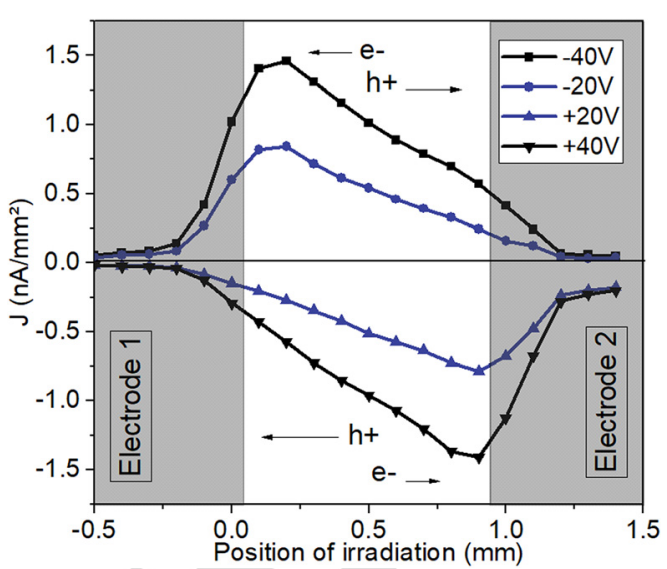

FIG. 5. Photocurrent density as a function of the position of the irradiation.

$$
\begin{gathered}
I_{m e s}(X)=\frac{1}{t_{m e s}} \times\left[\int n_{e_{-}}(x(t)) \exp \left(\frac{-t}{\tau_{e_{-}}}\right) \times \frac{e \mu_{e_{-}} E(x(t))}{L} d t\right. \\
\left.+\int n_{h_{+}}(x(t)) \exp \left(\frac{-t}{\tau_{h_{+}}}\right) \times \frac{e \mu_{h_{+}} E(x(t))}{L} d t\right],
\end{gathered}
$$

where $X$ is the irradiation position, $t_{\text {mes }}$ is the measurement time, $n$ is 157 the number of charge carriers created, $x(t)$ is the instantaneous posi- 158 tion of the charge carriers, $\tau$ is the charge carrier lifetimes, $e$ is the ele- 159 mentary charge, $\mu$ is the charge carrier mobilities, $E$ is the electric field, 160 and $L$ is the thickness of the sample.

Equation (3) shows that the photocurrent depends on both the 162 photocarriers' transport properties and the electric field distribution 163 along the thickness of the sample. With the ToF measurements, we 164 have established that the charge carriers' transport properties are dis- 165 symmetric $\left(\mu_{\mathrm{e}-} \tau_{\mathrm{e}-} \ll \mu_{\mathrm{h}+} \tau_{\mathrm{h}+}\right)$. If we hypothesize a constant electric 166 field, we expect to see a maximum of the photocurrent when the mate- 167 rial is irradiated near the anode and a minimum when it is irradiated 168 near the cathode. This is indeed what is observed on the photocurrent 169 profiles displayed in Figs. 5 and S8.

Here, electrode 1 is grounded while electrode 2 is biased. In the 171 case of charge creation near the anode (positive bias), the electrons are 172 collected almost immediately while the holes transit through the entire 173 thickness of the sample and account for most of the photocurrent 174 measured. In the case of charge creation near the cathode (negative 175 bias), the holes are collected almost immediately and, since the elec- 176 trons cannot transit through the entire thickness of the sample (as 177 demonstrated by the ToF experiments), the charge induced at the elec- 178 trode is lower than in the previous case. 179

In Fig. 5, it can also be observed that the photocurrent has non- 180 zero continuous values throughout the sample indicating a continuous 181 and non-null electric field. 182

In the discussion above, a constant electric field was hypothesized 183 to explain the shape of the photocurrent. However, the ToF data in 184 Fig. 2 have shown that a linear field, increasing from anode to cathode 185 is more likely. To get a better idea of the shape of the electric field, 186 Eq. (3) was used to model the X-ray focused and ToF experimental 187 results of sample 1 in the case of a constant electric field and a linear 188 electric field, increasing from anode to cathode (Figs. S9 and S10). 189 
We found that the x-ray focused experimental data could be modeled by either of those fields. However, only the linear electric field allowed modeling the ToF experimental data. This is in contradiction with the homogenous electric field hypothesis of Eq. (1). Nonetheless, the use of a constant electric field to model our data only leads to a $5 \%$ underestimation of the mobility, which is negligible compared to the $15 \%$ measurement uncertainty. More in depth modeling is under progress to achieve better fitting for both types of experimental data.

In conclusion, we have measured reproducible hole mobility of $\mathrm{MAPbBr}_{3}$ single crystals of controlled quality with laser ToF at $13 \mathrm{~cm}^{2}$ $\mathrm{V}^{-1} \mathrm{~s}^{-1} \pm 2 \mathrm{~cm}^{2} \mathrm{~V}^{-1} \mathrm{~s}^{-1}$. We have also seen that both ToF and $\mathrm{x}$-ray focused results are consistent with poor electrons' transport properties in $\mathrm{MAPbBr}_{3}$ single crystals. We can only hypothesize that the lack of electrons transit is due to either deep trapping levels or recombination centers, as shown by Musiienko et al. ${ }^{9}$ In the case of a deep trapping level, the detrapping constant would be higher than $100 \mathrm{~ms}$, our typical measurement duration. Finally, we have shown that the internal electric field exists throughout the thickness of the samples, and our preliminary modeling results point toward it being linear and increasing from anode to cathode. Knowing the nature of the electric field is essential and will therefore be the topic of follow-up studies.

See the supplementary material for detailed samples properties, ToF and x-ray focused measurements of samples 1-6, discussion about Hecht fitting, and discussion about the constant electric field hypothesis.

The authors thank Trixell and the ATTRACT project, from the European Horizon H2020 (Grant No. 777222, PerXi project), for the financial support.

\section{DATA AVAILABILITY}

The data that support the finding of this study are available from the corresponding authors upon reasonable request.

\section{REFERENCES}

${ }^{1}$ A. Kojima, K. Teshima, Y. Shirai, and T. Miyasaka, "Organometal halide perovskites as visible-light sensitizers for photovoltaic cells," J. Am. Chem. Soc. 131(17), 6050-6051 (2009).
${ }^{2}$ NREL. Best Research Cell Efficiency

${ }^{3}$ J. Li, H.-L. Cao, W.-B. Jiao, Q. Wang, M. Wei, I. Cantone, J. Lü, and A. Abate, 228 "Biological impact of lead from halide perovskites reveals the risk of introduc- 229 ing a safe threshold," Nat. Commun. 11(1), 310 (2020). 230

${ }^{4}$ Amari, S., Verilhac, J.-M., Gros D’Aillon, E., Ibanez, A., and Zaccaro, J., 231 "Optimization of the growth conditions for high quality 232 $\mathrm{CH}_{3} \mathrm{NH}_{3} \mathrm{PbBr}_{3}$ hybrid perovskite single crystals," Cryst. Growth Des. $\mathbf{\square}, 233$ (2020).

${ }^{5}$ D. Shi, V. Adinolfi, R. Comin, M. Yuan, E. Alarousu, A. Buin, Y. Chen, S. 235 Hoogland, A. Rothenberger, K. Katsiev et al., "Low trap-state density and long 236 carrier diffusion in organolead trihalide perovskite single crystals," Science 237 347(6221), 519-522 (2015).

${ }^{6}$ W. Wei, Y. Zhang, Q. Xu, H. Wei, Y. Fang, Q. Wang, Y. Deng, T. Li, A. 239 Gruverman, L. Cao et al., "Monolithic integration of hybrid perovskite single 240 crystals with heterogenous substrate for highly sensitive x-ray imaging," Nat. 241 Photonics 11(5), 315-321 (2017).

${ }^{7}$ H. Wei, Y. Fang, P. Mulligan, W. Chuirazzi, H.-H. Fang, C. Wang, B. R. Ecker, 243 Y. Gao, M. A. Loi, L. Cao et al., "Sensitive x-ray detectors made of methylam- 244 monium lead tribromide perovskite single crystals," Nat. Photonics 10(5), 245 333-339 (2016). 246

${ }^{8}$ H. Wei, D. DeSantis, W. Wei, Y. Deng, D. Guo, T. J. Savenije, L. Cao, and J. 247 Huang, "Dopant compensation in alloyed $\mathrm{CH}_{3} \mathrm{NH}_{3} \mathrm{PbBr}_{3-\mathrm{x}} \mathrm{Cl}_{\mathrm{x}}$ perovskite 248 single crystals for gamma-ray spectroscopy," Nat. Mater. 16(8), 826-833 249 (2017).

${ }^{9}$ A. Musiienko, P. Moravec, R. Grill, P. Praus, I. Vasylchenko, J. Pekarek, J. 251 Tisdale, K. Ridzonova, E. Belas, L. Landová et al., "Deep levels, charge trans- 252 port and mixed conductivity in organometallic halide perovskites," Energy 253 Environ. Sci. 12(4), 1413-1425 (2019). 254

${ }^{10}$ X. Wang, D. Zhao, Y. Qiu, Y. Huang, Y. Wu, G. Li, Q. Huang, Q. 255 Khan, A. Nathan, W. Lei et al., "PIN diodes array made of perovskite 256 single crystal for x-ray imaging," Phys. Status Solidi RRL 12(10), 257 1800380 (2018). 258

"E. Lukosi, T. Smith, J. Tisdale, D. Hamm, C. Seal, B. Hu, and M. Ahmadi, 259 "Methylammonium lead tribromide semiconductors: Ionizing radiation detec- 260 tion and electronic properties," Nucl. Instrum. Methods Phys. Res., Sect. A 927, 261 401-406 (2019).

${ }^{12}$ X. Liu, H. Zhang, B. Zhang, J. Dong, W. Jie, and Y. Xu, "Charge transport 263 behavior in solution-grown methylammonium lead tribromide perovskite 264 single crystal using $\alpha$ particles," J. Phys. Chem. C 122(26), 14355-14361 265 (2018).

${ }^{13}$ A. Musiienko, J. Pipek, P. Praus, M. Brynza, E. Belas, B. Dryzhakov, M.-H. Du, 267 M. Ahmadi, and R. Grill, Deciphering the Effect of Traps on the Electronic 268 Charge Transport Properties of Methylammonium Lead Tribromide Perovskites 269 (ם, 2019).

${ }^{14}$ International Standard, 2003).

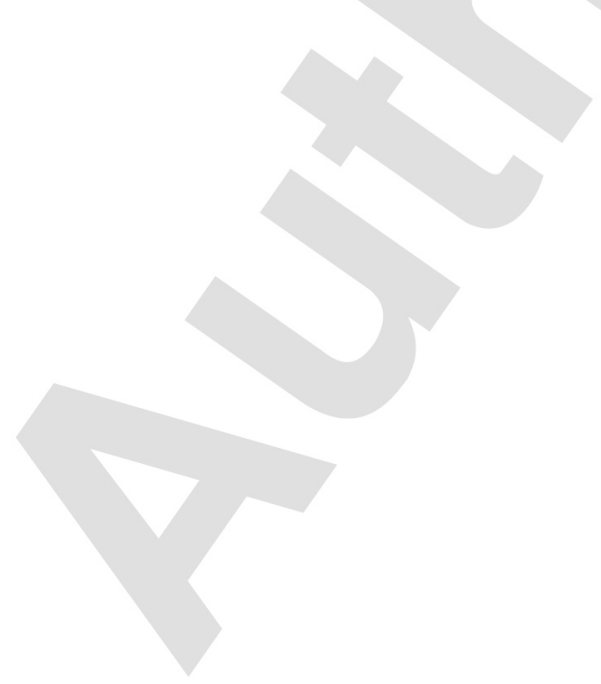

